\section{$\underset{\substack{\text { hommes } \\ \text { \& migrations }}}{ }$}

\section{Hommes \& migrations}

Revue française de référence sur les dynamiques

migratoires

1335 | 2021

Saisir le murmure du monde

\title{
Jean Birnbaum, Le courage de la nuance
}

Paris, Seuil, 2021, 144 p., $14 €$.Journaliste.

\section{Mustapha Harzoune}

\section{(2) OpenEdition}

1 Journals

\section{Édition électronique}

URL : https://journals.openedition.org/hommesmigrations/13471

DOI : 10.4000/hommesmigrations. 13471

ISSN : 2262-3353

Éditeur

Musée national de l'histoire de l'immigration

Édition imprimée

Date de publication : 1 octobre 2021

Pagination : 214-215

ISBN : 978-2-919040-59-9

ISSN : $1142-852 X$

\section{Référence électronique}

Mustapha Harzoune, « Jean Birnbaum, Le courage de la nuance », Hommes \& migrations [En ligne],

1335 | 2021, mis en ligne le 01 octobre 2021, consulté le 26 février 2022. URL : http://

journals.openedition.org/hommesmigrations/13471; DOI : https://doi.org/10.4000/

hommesmigrations. 13471 


\section{Le courage de la nuance}

Jean Birnbaum, Paris, Seuil, 2021, 144 p., $14 €$.

Directeur du Monde des Livres, essayiste, auteur notamment d'Un silence religieux. La gauche face au djihadisme (Seuil, 2016) et de La religion des faibles. Ce que le djihadisme dit de nous (Seuil, 2018), 


\section{Jean \\ Birnbaum \\ COURAGE \\ DE LA \\ NUANCE}

\author{
Sout
}

Jean Birnbaum avait besoin d'air, de distance, non pas de recul - car on peut garder sa distance sans céder un pouce de son espace vital - mais d'ancrage, d'une position plus assurée pour faire face au désordre étouffant, aux gesticulations des certitudes qui nous environnent. Retrouver un peu d'équilibre. «En fait, l'équilibre est un effort et un courage de tous les instants. La société qui aura ce courage est la vraie société de l'avenir » dit Camus dans une conférence donnée à Athènes en 1955 - ici repris par l'auteur. Ce «bref manuel de survie par temps de vitrification idéologique» est écrit pour affronter les logiques binaires - et conflictuelles - de l'un contre l'autre, l'acrimonie des réseaux sociaux, les simplifications des appartenances univoques, la médiocrité des pensées... Retrouver (un peu) d'équilibre. Pour ce faire, Birnbaum utilise un mot qui, à l'origine, renvoie au mélange, à l'assortiment des «couleurs nuées», selon la première édition du Dictionnaire de l'Académie française (1694), autrement dit "disposer des couleurs de façon harmonieuse». Ainsi, la «nuance» suppose plusieurs couleurs et une forme commune dans laquelle chacune puisse trouver à s'exprimer. Un tout qui ne se résumerait pas à ses parties et des parties qui ne disparaîtraient pas dans un tout. Sans doute que, par les temps qui courent, il en faut du courage pour oser la nuance, «cet héroïsme de la mesure». Par les temps qui courent seulement? Non bien sûr, et Camus, Bernanos, Arendt, Aron, Orwell, Tillion, Barthes le prouvent ici. Ces «figures aimées», écrit l'auteur, «peuvent nous aider à tenir bon, à nous tenir bien». Leurs œuvres et leur vie ne peuvent que renforcer le goût pour «une liberté intraitable, une éthique de la vérité, la conscience de nos limites, le sens de l'humour, un rapport à l'inconscient, une morale du langage, le goût de la franchise, un art de l'amitié... ». Rien moins! Et cela fonctionne. Renforce et stimule. Oblige aussi car s'«il n'y a pas plus radical que la nuance», il n'y a pas aussi plus exigeant. Il faut sans cesse peser ses pensées et ses actions au trébuchet du «pluralisme» de la civilisation européenne (Camus), au trébuchet de nos aveuglements, de nos refus de «voir» les barbaries à venir (Bernanos), de l'ironie et de l'amitié (Arendt), de l'«éthique intraitable du doute» et de l'incertitude (Aron), d'une mémoire longue et d'un langage libre, indispensables constituants de la franchise et de la possibilité même du dialogue (Orwell), de l'exigence de vérité (Tillion), de la littérature, «maîtresse des nuances» (Roland Barthes). «La science est grossière, la vie est subtile, et c'est pour corriger cette distance que la littérature nous importe» disait le professeur au Collège de France. Au trébuchet aussi d'une langue simple et élégante, une langue qui est tout sauf banale. Car la «banalité du mal» est d'abord affaire de discours. "L'homme du mal ne dit que des banalités», "débite de misérables stéréotypes». Terrible rappel et salutaire alerte.

Tous invitent à ne pas mésestimer «les forces obscures» qui nous traversent. "On ne se méfie jamais assez de soi-même» dit Bernanos et, pour Germaine Tillion, "l'humanité, c'est quelque chose de dangereux». "Le reconnaitre oblige à une forme d'humilité» écrit l'auteur.

Il y a de l'héroïsme ici! Car il faut être un héros pour douter, oser appeler à la prudence, convoquer l'incertitude, privilégier la compréhension sur les anathèmes, faire l'effort de penser poétiquement le monde plutôt que de le réduire à des formules et des certitudes, préférer les armes de l'élégance et de l'ironie aux barbelés et aux pelotons d'exécution. Les méridiens de Greenwich de la pensée ont vite fait de clouer au pilori, d'accuser les uns et les autres "de faire le jeu de...» - «l'un des grands anathèmes propres aux "méthodes totalitaires de la controverse"» (Orwell).

Tous appartiennent au cercle étroit des «artistes en rupture» comme l'a nommé en son temps Linda Lê (Par ailleurs (Exils), Christian Bourgois, 2014). Ce sont des exilés en terre d'écriture, qui refusent «d'être assignés à résidence», qui cultivent la mobilité et parfois l'échappée, le contrepoint et parfois une (heureuse) dissonance. "Les femmes et les hommes que j'ai voulu réunir dans ce livre ne savaient pas où se mettre. Ils étaient trop nuancés pour s'aligner sur des slogans. Trop libres pour supporter la discipline d'un parti. Trop sincères pour renoncer à la franchise. Trop mobiles pour obéir à la police des frontières, que ces frontières soient politiques ou littéraires», écrit Pierre Birnbaum, comme en écho à Bernanos: "L'homme de bonne volonté n'a plus de parti. Je me demande s'il aura demain une patrie.»

M. H. 